\title{
Mn-Cr ages of Fe-rich olivine in two Rumuruti (R) chondrites
}

\author{
Naoji Sugiura and Akiko Miyazaki \\ Department of Earth and Planetary Science, The University of Tokyo, Tokyo, Japan \\ (Received October 27, 2005; Revised February 24, 2006; Accepted February 28, 2006; Online published May 12, 2006)
}

\begin{abstract}
Mn- $\mathrm{Cr}$ systematics in olivine of two Rumuruti (R) chondrites was investigated. $\mathrm{Mn} /{ }^{52} \mathrm{Cr}$ ratios up to 1800 and 1300, and $\delta^{53} \mathrm{Cr}$ of up to $25 \%$ and $7 \%$ were observed for NWA 753 and Sahara 99531 , respectively. All data points of NWA 753 show a linear correlation between $\delta^{53} \mathrm{Cr}$ values and $\mathrm{Mn} /{ }^{52} \mathrm{Cr}$ ratios on the isochron diagram. The inferred initial ${ }^{53} \mathrm{Mn} /{ }^{55} \mathrm{Mn}$ ratio for NWA 753 is $(1.84 \pm 0.42(2 \sigma)) \times 10^{-6}$. In the case of Sahara 99531, a positive correlation interpreted as an isochron for ${ }^{53} \mathrm{Mn} /{ }^{55} \mathrm{Mn}=2.75 \pm 1.55(2 \sigma) \times 10^{-6}$ was obtained for only one chondrule. Data from other chondrules in Sahara 99531 give an upper limit of ${ }^{53} \mathrm{Mn} /{ }^{55} \mathrm{Mn}=0.49 \times 10^{-6}$. The Mn-Cr ages of NWA 753 and a chondrule in Sahara 99531 are slightly older than that of the angrite LEW 86010 (Lugmair and Shukolyukov, 1998). Other chondrules in Sahara 99531 are at least 5 Ma younger than the LEW 86010. The Mn-Cr ages of olivine in R chondrites correspond to the time when olivine became a closed system either during slow cooling from the peak metamorphic temperature or during rapid cooling by impact excavation. In either case the olivine closure occurred earlier than the final assembly of the brecciated chondrites.
\end{abstract}

Key words: Age, chondrites, olivine, $\mathrm{Mn}, \mathrm{Cr}$.

\section{Introduction}

Rumuruti (R) chondrites are a small group of meteorites that are highly oxidized (Bischoff et al., 1994; Rubin and Kallemeyn, 1994; Schulze et al., 1994) and have unique oxygen isotopic compositions (Weisberg et al., 1991; Bischoff et al., 1994). Oxygen isotopic compositions of chondrules in $\mathrm{R}$ chondrites suggest that they may be related to ordinary chondrites (Greenwood et al., 2000). R chondrites are rich in volatile elements such as $\mathrm{Zn}$ compared with ordinary chondrites (Kallemeyn et al., 1996), which may be attributed to a higher proportion of matrix in $\mathrm{R}$ chondrites compared with ordinary chondrites. The oxidation of $\mathrm{R}$ chondrites may have partly occurred in the parent body during the aqueous alteration and subsequent thermal metamorphism (Greenwood et al., 2000) though oxidation in a nebula environment cannot be ruled out (e.g. Weisberg et al., 1991).

The thermal history of $\mathrm{R}$ chondrites is poorly known. Hibonites in a CAI in an $\mathrm{R}$ chondrite were dated by the $\mathrm{Al}-\mathrm{Mg}$ system to be $3 \mathrm{Ma}$ younger than the canonical age of CAIs (Bischoff and Srinivasan, 2003). Since hibonite appears to be resistant to secondary alteration and since solid grains are unlikely to be kept for $3 \mathrm{Ma}$ in the nebula, this age of hibonite probably reflects partial resetting of the $\mathrm{Al}-\mathrm{Mg}$ system by alteration in the $\mathrm{R}$ chondrite parent body. ${ }^{39} \mathrm{Ar}-{ }^{40} \mathrm{Ar}$ ages are known for four $\mathrm{R}$ chondrites (Dixon et al., 2003). The peak ${ }^{39} \mathrm{Ar}-{ }^{40} \mathrm{Ar}$ ages range from 4.30 to $4.47 \mathrm{Ga}$. Because of this wide range in the peak ${ }^{39} \mathrm{Ar}-$ ${ }^{40} \mathrm{Ar}$ ages, and because of low closure temperatures of the K-Ar system (100-360 C; Turner et al., 1978) it is rather

Copyright (c) The Society of Geomagnetism and Earth, Planetary and Space Sciences (SGEPSS); The Seismological Society of Japan; The Volcanological Society of Japan; The Geodetic Society of Japan; The Japanese Society for Planetary Sciences; TERRAPUB. unlikely that these ages reflect slow cooling after thermal metamorphism. Three of these $\mathrm{R}$ chondrites are regolith breccias and hence the Ar-Ar ages may date shock-heating events before (or at the time of) final assembly of the $\mathrm{R}$ chondrites. Many R chondrites contain fairly large amounts of ${ }^{129} \mathrm{Xe}$ (Schultz et al., 2005). Although it does not provide quantitative measure of $\mathrm{Xe}$ closure age, a high ${ }^{129} \mathrm{Xe} /{ }^{132} \mathrm{Xe}$ ratio in a chondrite suggests early closure.

In summary, it is yet poorly known when metamorphism and oxidation ended in the $\mathrm{R}$ chondrite parent body. Fe-rich olivine is a major constituent of $\mathrm{R}$ chondrites that resulted from metamorphism and oxidation. It is rich in $\mathrm{Ni}$ and $\mathrm{Mn}$ and poor in $\mathrm{Cr}$, reflecting oxidizing conditions during its formation (Kallemeyn et al., 1996). This olivine can be dated by the ${ }^{53} \mathrm{Mn}-{ }^{53} \mathrm{Cr}$ system. Here we report $\mathrm{Mn}-\mathrm{Cr}$ ages of Fe-rich olivine in two $\mathrm{R}$ chondrites (Northwest Africa (NWA) 753 and Sahara 99531).

Sahara 99531 (Fig. 1(a)) is a typical R chondrite (R3-5). It is a regolith breccia containing solar rare gases (Schultz and Weber, 2001), which suggests that this meteorite was not heated to high temperatures after the final assembly. NWA 753 (Fig. 1(b)) is assigned to type 3.9. It is a breccia and the section we examined consists of two lithologies. One (lithology A) is primitive and not highly oxidized (containing many sulfides and chondrules with low $\mathrm{Fe} / \mathrm{Mg}$ silicates). The presence of clasts of primitive materials similar to the lithology-A in NWA 753 has been reported in various R chondrites (Bischoff, 2000). Second lithology (lithology-B) is more similar to typical R chondrites (e.g. Sahara 99531). NWA 753 seems to contain no solar rare gases (Schultz and Weber, 2001). However, the presence of a primitive clast suggests that this $\mathrm{R}$ chondrite was not reheated to high temperatures after the final assembly. NWA 753 gives ${ }^{129} \mathrm{Xe} /{ }^{132} \mathrm{Xe}=2.24$ whereas Sahara 99531 gives 


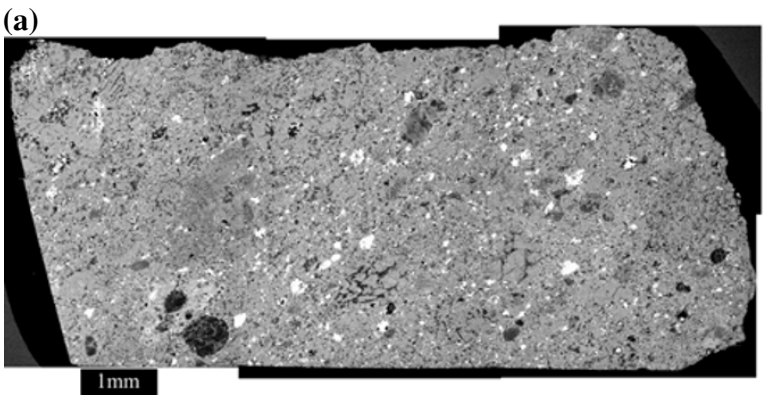

(b)

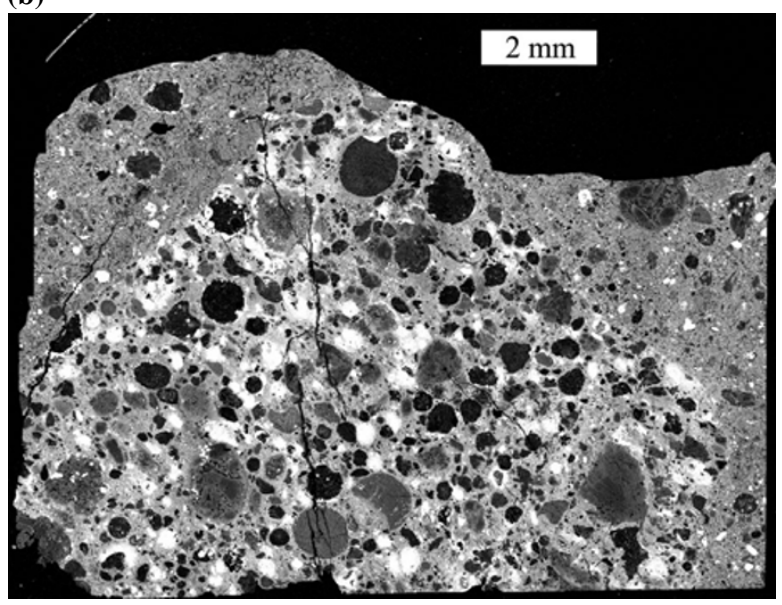

(c)

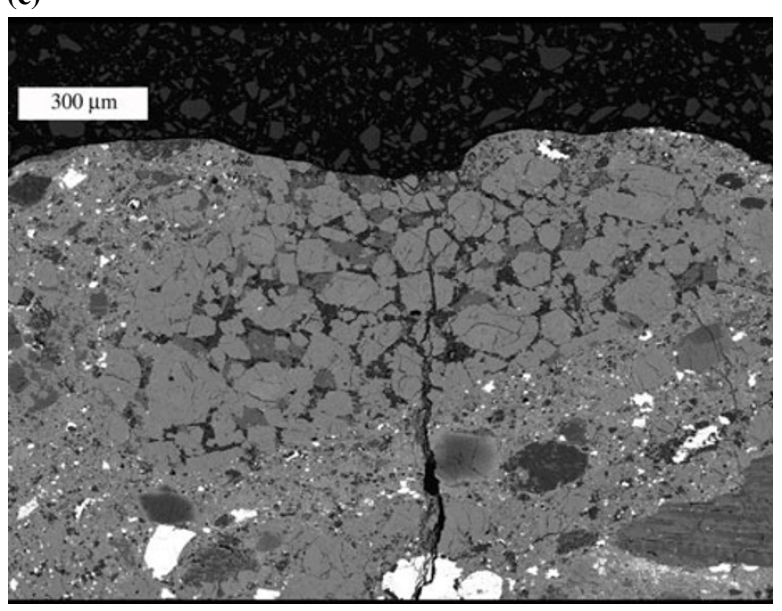

Fig. 1. Backscattered electron micrographs. a) Sahara 99531. Olivine with $\mathrm{Fe} /(\mathrm{Fe}+\mathrm{Mg}) \sim 0.4$ appears grey. Darker grains are magnesian olivine and pyroxene. White grains are sulfides. b) NWA 753 consists of two lithologies. The central area, rich in chondrules and sulfides is called lithology-A. Greyish areas at the upper left corner and the right-hand side are called lithology-B. c) Chondrule \#1 in NWA 753 is located at the center of the image. It is a large elongated porphyritic chondrule, consisting of many $\mathrm{Fe}$-rich olivine grains.

${ }^{129} \mathrm{Xe} /{ }^{132} \mathrm{Xe}=1.26$ (Schultz et al., 2005). These Xe data also suggest that NWA 753 is more primitive than Sahara 99531.

\section{Experimental}

Polished sections of these $\mathrm{R}$ chondrites were examined with a scanning electron microscope (JEOL-5310). Chemical compositions of olivine grains were measured with energy dispersive spectroscopy (Oxford Instruments).

An ion probe (Cameca-6f) at the Univ. of Tokyo was used for the $\mathrm{Mn}-\mathrm{Cr}$ isotope measurement. Both ${ }^{52} \mathrm{Cr}$ and ${ }^{53} \mathrm{Cr}$ were measured with an electron multiplier whereas Mn was measured with a Faraday cup. We assumed that instrumental isotopic fractionation effects on the $\mathrm{Cr}$ isotopic composition were constant and did not monitor ${ }^{50} \mathrm{Cr}$. In the case of $\mathrm{Mn}-\mathrm{Cr}$ dating of phosphates (Sugiura and Hoshino, 2003), ${ }^{52} \mathrm{Cr} /{ }^{50} \mathrm{Cr}$ was used for estimating the instrumental isotopic fractionation. In the case of olivine, however, ${ }^{50} \mathrm{Cr}$ cannot be measured accurately because of severe ${ }^{50} \mathrm{Ti}$ interference and hence ${ }^{52} \mathrm{Cr} /{ }^{50} \mathrm{Cr}$ cannot be used for estimating instrumental effects (Hsu, 2005). Fortunately, a running standard (San Carlos olivine) and many Mg-rich, Mn-poor olivine in the $\mathrm{R}$ chondrites showed nearly constant ${ }^{53} \mathrm{Cr} /{ }^{52} \mathrm{Cr}$ ratios. Therefore, deviation of the ${ }^{53} \mathrm{Cr} /{ }^{52} \mathrm{Cr}$ ratios observed by repeated measurements $(1.9 \%$ at $1 \sigma)$ of the San Carlos olivine was used for assessing the deviation of instrumental mass fractionation and propagated to the errors of all measurements.

The Fe-rich olivine grains in $\mathrm{R}$ chondrites often contain tiny speckles of chromite and/or cracks filled with $\mathrm{Cr}$ rich materials that appear to have been produced during the metamorphism. SIMS measurements were made on olivine grains that are devoid of such chromite/Cr-rich materials. In one object (chondrule, fragment of chondrule or isolated olivine) of NWA 753, usually only one spot can be analyzed because of the presence of $\mathrm{Cr}$-rich materials. However, chondrule \#1 (Fig. 1(c)) is a large porphyritic chondrule consisting of many large olivine grains, hence, 6 points were analyzed. Sahara 99531 contains many porphyritic chondrules some of which are devoid of Cr-rich materials. Several olivine grains were analyzed in 3 such chondrules. Fe-poor, Cr-rich olivine grains were also measured to determine the $y$-intercept of isochrons. However, such grains devoid of chromite speckles were rare in both $\mathrm{R}$ chondrites. Therefore, data for the San Carlos olivine are also used for accurate determination of y-intercept. The lithology-A in NWA 753 did not contain large olivine grains with high $\mathrm{Mn} / \mathrm{Cr}$ ratios because it did not experience much metamorphic heating that caused loss of $\mathrm{Cr}$ from the olivine grains. Therefore, chronological data are not reported for this lithology.

The primary $\mathrm{O}^{-}$beam size is $30 \sim 40 \mu \mathrm{m}$ in diameter and the intensity is $4 \sim 10 \mathrm{nA}$. Counting rates of ${ }^{52} \mathrm{Cr}$ are $\geq 150 \mathrm{cps}$ for $\mathrm{Cr}$-poor olivine. The ${ }^{52} \mathrm{Cr}$ signal was measured for 1 second whereas the ${ }^{53} \mathrm{Cr}$ signal was measured for 6 seconds per cycle. On the order of 500 cycles of isotopic data are obtained at one spot. The mass-resolving power was set to $\sim 4500$. This is not enough to separate ${ }^{52} \mathrm{CrH}$ ions from ${ }^{53} \mathrm{Cr}$ ions but the ${ }^{52} \mathrm{CrH}$ signal (which is practically undetectable during the mass calibration procedure) was always less than $1 \%$ of the ${ }^{53} \mathrm{Cr}$ signal. The relative sensitivity factor $\left(\mathrm{Mn}^{+} / \mathrm{Cr}^{+}\right) /(\mathrm{Mn} / \mathrm{Cr})=1.62 \pm 0.12$ ( $2 \sigma$ error) was estimated based on measurements of a synthetic glass sample which has a composition similar to the Fe-rich olivine in R chondrites (Sugiura et al., 2005).

\section{Results}

Fayalite content in chondrules and matrices are shown in Fig. 2. Magnesium-rich olivine grains are heterogeneous in composition, with $\mathrm{Fe}$ increasing toward the edges. 

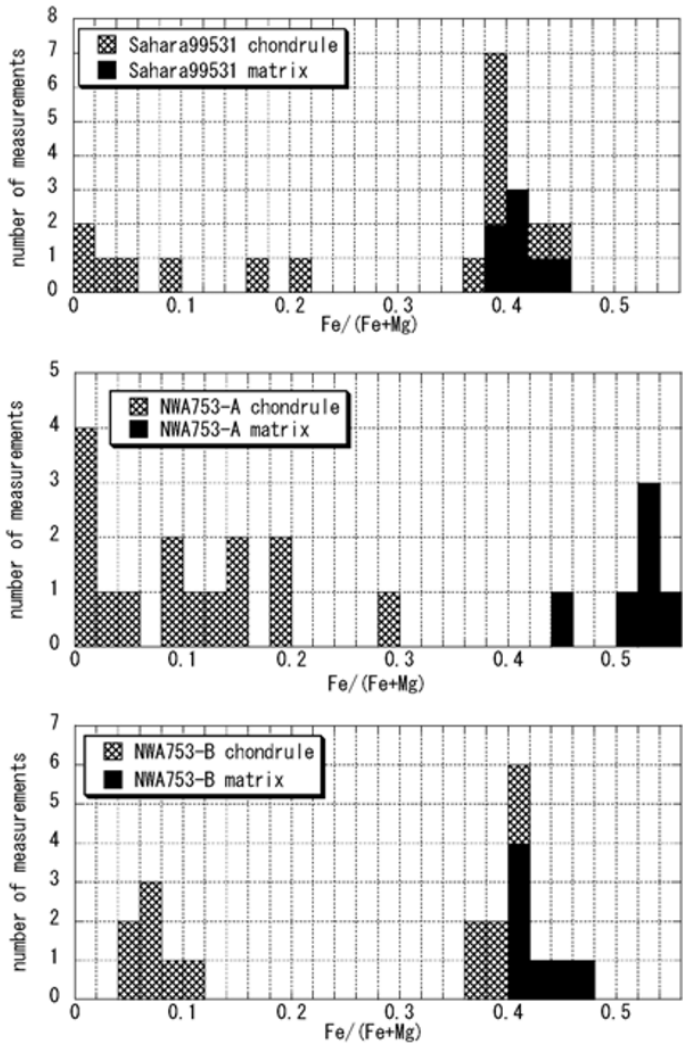

Fig. 2. Histograms showing variation in fayalite content in chondrules and matrices in Sahara 99531 (top), NWA 753 lithology-A (center) and NWA 753 lithology-B (bottom). Matrix olivines are rich in Fe. Olivines in many chondrules and chondrule fragments are also rich in Fe in Sahara 99531 and lithology-B in NWA 753. The number of measurements in these histograms is not proportional to the real number of grains in the samples. As shown in the electron micrographs (Fig. 1), Fe-rich olivines are predominant in Sahara 99531 and NWA 753 lithology-B.

Olivine compostions at the centers of large grains are shown in Fig. 2. Matrix olivines are rich in Fe. Olivines in many chondrules and chondrule fragments are also rich in $\mathrm{Fe}$ in Sahara 99531 and lithology-B in NWA 753. In the lithology-A of NWA 753, magnesium-rich olivine is abundant, confirming its primitive nature. Magnesium-rich olivine in lithology-B in NWA 753 seems to have a restricted range of $\mathrm{Fe}$ content.

$\mathrm{Mn} /{ }^{52} \mathrm{Cr}$ ratios and $\delta^{53} \mathrm{Cr}$ values in the $\mathrm{R}$ chondrites are summarized in Table $1 . \mathrm{Mn} /{ }^{52} \mathrm{Cr}$ ratios up to 1800 and 1300 were observed for lithology-B in NWA 753 and Sahara 99531, respectively. $\delta^{53} \mathrm{Cr}$ values of up to $25 \%$ and 7 $\%$ were observed for the NWA 753 and the Sahara 99531, respectively (Fig. 3). The inferred initial ${ }^{53} \mathrm{Mn} /{ }^{55} \mathrm{Mn}$ ratios and the corresponding ages relative to the angrite LEW 86010 are given in Table 2.

The effects of cosmogenic ${ }^{53} \mathrm{Cr}$ are considered to be negligible. In the case of typical IIIAB iron meteorites with an exposure age of $\sim 650 \mathrm{Ma}$, the cosmogenic effect was estimated to be $\delta^{53} \mathrm{Cr} \sim\left(1.7 \times 10^{-4} \% o\right) \times\left({ }^{56} \mathrm{Fe} /{ }^{52} \mathrm{Cr}\right.$ ) (Sugiura and Hoshino, 2003. Note that the formula given there is incorrect.). Though production rates of cosmogenic $\mathrm{Cr}$ in $\mathrm{R}$ chondrites may be somewhat different from those in iron meteorites, this relation could be used for a rough esti-
Table 1. Mn-Cr systematics in $\mathrm{R}$ chondrites.

\begin{tabular}{|c|c|c|c|}
\hline & $\mathrm{Mn} /{ }^{52} \mathrm{Cr}$ & $\delta^{53} \mathrm{Cr}(\% o)$ & $\delta^{53} \mathrm{Cr}$ error $(\% o)$ \\
\hline \multicolumn{4}{|l|}{ NWA 753} \\
\hline \#1-1 & 1014.9 & 24.9 & 4.6 \\
\hline$\# 1-2$ & 619.9 & 10.7 & 5.9 \\
\hline$\# 1-3$ & 1476.1 & 23.4 & 5.4 \\
\hline$\# 1-4$ & 755.3 & 13.5 & 3.9 \\
\hline$\# 1-5$ & 754.9 & 15.1 & 6.7 \\
\hline \#1-6 & 734.1 & 14.3 & 4.3 \\
\hline$\# 2$ & 1820.4 & 25.2 & 11.0 \\
\hline$\# 3$ & 944.8 & 11.8 & 4.4 \\
\hline$\# 4$ & 11.4 & -1.9 & 2.2 \\
\hline$\# 5$ & 370.7 & 10.9 & 4.3 \\
\hline$\# 6$ & 257.1 & 0.9 & 3.4 \\
\hline$\# 7$ & 716.3 & 5.6 & 5.6 \\
\hline$\# 8$ & 11.3 & 5.2 & 2.4 \\
\hline$\# 9$ & 0.1 & -1.3 & 2.3 \\
\hline$\# 10$ & 2.1 & 3.1 & 2.1 \\
\hline \#11 & 0.1 & 1.5 & 2.2 \\
\hline \#12 & 3.3 & 1.7 & 2.1 \\
\hline San Carlos olivine & 4.0 & -2.1 & 2.2 \\
\hline San Carlos olivine & 4.0 & -0.5 & 2.1 \\
\hline San Carlos olivine & 4.0 & -1.3 & 2.2 \\
\hline San Carlos olivine & 4.0 & 3.7 & 2.2 \\
\hline San Carlos olivine & 4.0 & 0.5 & 2.2 \\
\hline San Carlos olivine & 4.0 & 1.6 & 2.4 \\
\hline San Carlos olivine & 4.0 & 0.6 & 2.3 \\
\hline San Carlos olivine & 3.9 & 1.8 & 2.3 \\
\hline San Carlos olivine & 3.9 & 1.4 & 2.3 \\
\hline San Carlos olivine & 4.0 & 0.4 & 2.4 \\
\hline San Carlos olivine & 4.0 & -0.2 & 2.3 \\
\hline \multicolumn{4}{|l|}{ Sahara 99531} \\
\hline \#1-1 & 1189.9 & 1.5 & 6.1 \\
\hline$\# 1-2$ & 1289.0 & 1.6 & 6.8 \\
\hline$\# 1-3$ & 1310.8 & -10.9 & 6.5 \\
\hline \#2-1 & 261.7 & 6.4 & 2.8 \\
\hline \#2-2 & 211.9 & 5.2 & 3.3 \\
\hline \#2-3 & 163.5 & 3.2 & 3.2 \\
\hline \#2-4 & 319.5 & 5.8 & 4.1 \\
\hline$\# 2-5$ & 321.4 & 6.2 & 3.9 \\
\hline \#3-1 & 456.0 & 2.7 & 5.3 \\
\hline$\# 3-2$ & 264.0 & -0.9 & 4.3 \\
\hline$\# 4$ & 1.3 & -0.7 & 2.0 \\
\hline San Carlos olivine & 12.4 & -2.0 & 2.9 \\
\hline San Carlos olivine & 13.2 & -0.3 & 3.0 \\
\hline San Carlos olivine & 12.4 & -2.0 & 2.9 \\
\hline San Carlos olivine & 4.0 & 0.3 & 2.0 \\
\hline San Carlos olivine & 4.1 & 0.9 & 2.1 \\
\hline San Carlos olivine & 4.0 & -1.2 & 2.1 \\
\hline
\end{tabular}

Errors are $1 \sigma$.

mate of the cosmogenic effect in $\mathrm{R}$ chondrites. For Fe-rich olivine with $\mathrm{Mn} /{ }^{52} \mathrm{Cr} \sim 1000$ and $\mathrm{Fe} / \mathrm{Mn} \sim 70$ in $\mathrm{R}$ chondrites with an exposure age of $\sim 30 \mathrm{Ma}$, the cosmogenic correction is estimated to be less than 1\%o. The exposure age of Sahara 99531 is $\sim 27.9 \mathrm{Ma}$ (Schultz and Weber, 2001). It did not show appreciable excesses in ${ }^{53} \mathrm{Cr}$ in some of the Fe-rich olivine, confirming the insignificance of the cosmogenic effect. The exposure age of NWA 753 is 25 Ma (Ebisawa et al., 2003) and hence the cosmogenic effect is expected to be slightly smaller than that in Sahara 99531. The insignif- 
Table 2. Mn initial ratios and $\mathrm{Mn}-\mathrm{Cr}$ ages of $\mathrm{R}$ chondrites.

\begin{tabular}{lcc}
\hline Sample & ${ }^{53} \mathrm{Mn} /{ }^{55} \mathrm{Mn} \pm 2 \sigma$ error & Age from LEW 86010 \\
\hline NWA 753 \& San Carlos olivine & $(1.84 \pm 0.44) \times 10^{-6}$ & $-2.07 \mathrm{Ma}$ \\
Sahara 99531 \#1+\#3+\#4 \& San Carlos olivine & $(-1.30 \pm 6.20) \times 10^{-7}$ & $>5.01$ Ma (lower limit) \\
Sahara 99531 \#2+\#4 \& San Carlos olivine & $(2.75 \pm 1.56) \times 10^{-6}$ & $-4.22 \mathrm{Ma}$ \\
\hline
\end{tabular}

The $2 \sigma$ errors include the uncertainty of the relative sensitivity factor. Sahara 99531 \#4 is a magnesian olivine in a chondrule.

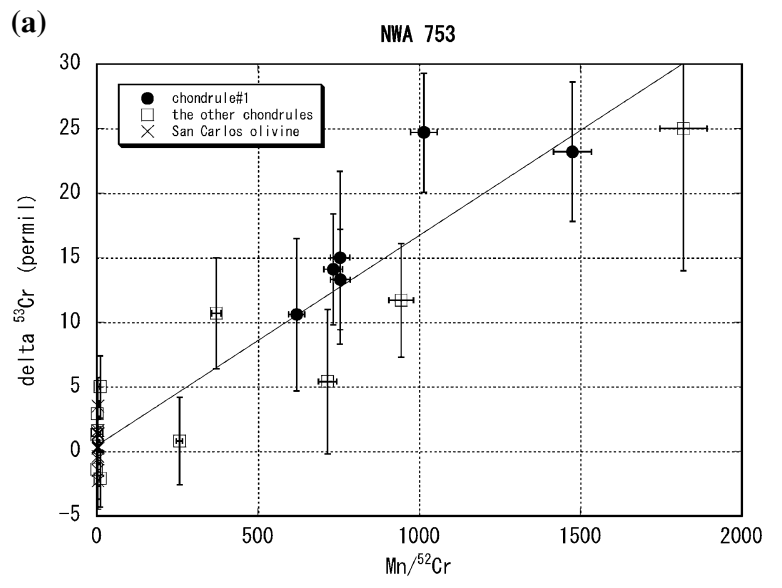

(b)

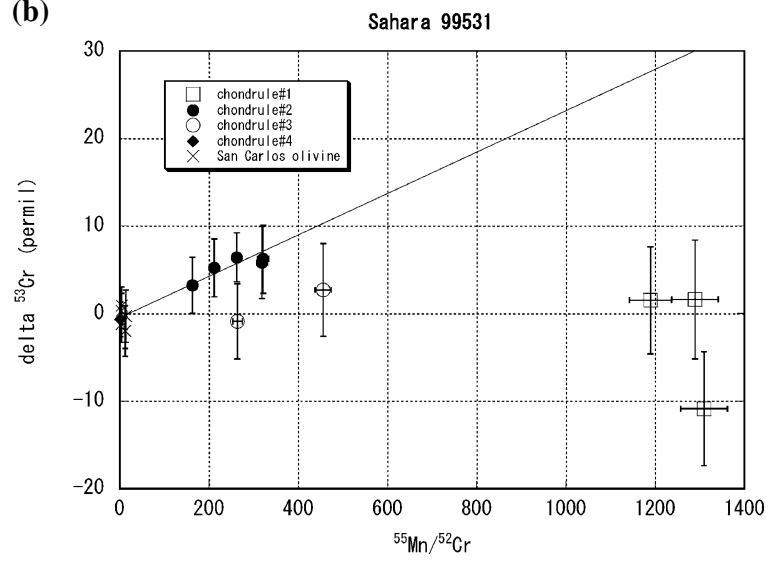

Fig. 3. a) Mn-Cr isochron diagram for NWA 753. The chondrule \#1, the other chondrules and the San Carlos olivine are shown by different symbols. The isochron was drawn using all the data. b) Mn-Cr isochron diagram for Sahara 99531. Various chondrules and San Carlos olivine data are shown by different symbols. The isochron was drawn using the chondrules \#2, chondrule \#4 (Fe-poor olivine) and San Carlos olivine. The error bars are $1 \sigma$.

icance of the cosmogenic effect in ordinary chondrites was shown based on the production rate of ${ }^{53} \mathrm{Mn}$ by cosmic-ray spallation reactions (Nyquist et al., 2001). Hsu (2005) also reached a similar conclusion that the cosmogenic effect is negligible in the case of pallasite olivine. Therefore, no correction was made for the cosmogenic effect for the $\mathrm{R}$ chondrites.

All the data for NWA 753 show fairly good correlation (isochron) between the excesses in ${ }^{53} \mathrm{Cr}$ and $\mathrm{Mn} /{ }^{52} \mathrm{Cr}$ ratios. The inferred initial ${ }^{53} \mathrm{Mn} /{ }^{55} \mathrm{Mn}$ ratio is $(1.84 \pm$ $0.42(2 \sigma)) \times 10^{-6}$. This translates to an age of $2.1 \mathrm{Ma}$ before the angrite LEW 86010 (Lugmair and Shukolyukov, 1998) and 8.7 Ma after chondrules in ordinary chondrites
(Nyquist et al., 2001). For Sahara 99531, a chondrule (chondrule \#2) showed positive $\delta^{53} \mathrm{Cr}$ values that are correlated with the $\mathrm{Mn} / \mathrm{Cr}$ ratios, although both the $\mathrm{Mn} / \mathrm{Cr}$ ratios and the $\delta^{53} \mathrm{Cr}$ anomalies are small. Other Fe-rich chondrules (chondrule \#1 and \#3) seem to show no excesses of ${ }^{53} \mathrm{Cr}$. The inferred initial ${ }^{53} \mathrm{Mn} /{ }^{55} \mathrm{Mn}$ ratio of chondrule \#2 is $(2.75 \pm 1.56(2 \sigma)) \times 10^{-6}$, and its $\mathrm{Mn}-\mathrm{Cr}$ age is about 4 Ma before LEW 86010. The ages of the other chondrules (\#1 and \#3) in Sahara 99531 are at least 5 Ma younger than that of LEW 86010. Using the absolute age of LEW 86010 (4557.8 Ma: Lugmair and Shukolyukov, 1998) the absolute ages of NWA 753 and the chondrule \#2 in Sahara 99531 are 4559.9 Ma and 4562.0 Ma, respectively. The other chondrules in Sahara 99531 are younger than 4552.8 Ma.

\section{Discussion}

Our data show Mn-Cr ages of NWA 753 and a chondrule in Sahara 99531 are much older than the ${ }^{39} \mathrm{Ar}-{ }^{40} \mathrm{Ar}$ ages (4.30 to $4.47 \mathrm{Ga}$ ) reported for $\mathrm{R}$ chondrites (Dixon et al., 2003). This is probably because the Mn-Cr system is generally more robust than the ${ }^{39} \mathrm{Ar}-{ }^{40} \mathrm{Ar}$ system which is easily reset by mild shock. Therefore, the old $\mathrm{Mn}-\mathrm{Cr}$ ages of NWA 753 and the chondrule \#2 in Sahara 99531 are not inconsistent with the much younger ${ }^{39} \mathrm{Ar}-{ }^{40} \mathrm{Ar}$ ages reported for $\mathrm{R}$ chondrites. The $\mathrm{Mn}-\mathrm{Cr}$ ages of $\mathrm{R}$ chondrites are significantly younger than the ages of chondrules in primitive chondrites which are $\sim 4565 \mathrm{Ma}$ (Kita et al., 2000). Therefore, it is likely that the Mn-Cr ages of olivine in NWA 753 and the chondrule \#2 in Sahara 99531 correspond to the time when olivine became a closed system during cooling from the peak metamorphic temperature in the parent body. Assuming closure during slow cooling, the closure temperature can be estimated based on the cooling rate, the grain size and the $\mathrm{Cr}$ diffusion rates (Ito and Ganguly, 2006). The cooling rate $(\sim 20 \mathrm{C} / \mathrm{Ma})$ is roughly estimated to be consistent with the age data. Then, assuming a typical grain size of $50 \mu \mathrm{m}$, the closure temperature is estimated to be $\sim 640$ C from Fig. 6 of Ito and Ganguly (2006). This closure of olivine probably occurred earlier than the final assembly of the brecciated chondrite. These $\mathrm{Mn}-\mathrm{Cr}$ ages of $\mathrm{R}$ chondrites are similar to those of fayalite in carbonaceous chondrites (Krot et al., 2000; Hua et al., 2005).

Although the chondrule \#2 in Sahara 99531 is old, the other chondrules (\#1 and \#3) in Sahara 99531 are young. Since Sahara 99531 is a breccia, this is not a problem. The old chondrule is relatively rich in $\mathrm{Cr}$ compared with the younger Fe-rich chondrules, which is reflected by the small Mn/Cr ratios of the former (Fig. 3(b)). This suggests that the younger chondrules experienced continued metamorphism that caused more $\mathrm{Cr}$ loss from the olivine grains. 
If we assume that ages of these chondrules reflect closure of the Mn-Cr system during slow cooling from the peak metamorphic temperature which was attained by ${ }^{26} \mathrm{Al}$ decay, then the age difference provides a crude measure of the difference in the depth in the parent body, which is briefly described below.

The absolute age of CAIs is $\sim 4568$ Ma although the exact age is yet to be determined (Amelin et al., 2002; Baker et al., 2005). The $\mathrm{R}$ chondrite parent body must have accreted at $\sim 4566 \mathrm{Ma}$. If the parent body accreted much earlier, it is molten by the heat due to ${ }^{26} \mathrm{Al}$ decay. If it accreted much later, then there was no heat source for thermal metamorphism. A peak metamorphic temperature was reached at $\sim 4564 \mathrm{Ma}$. Therefore, the old chondrule \#2 ( 4562 Ma) in Sahara 99531 became a closed system in 2 Ma after the peak metamorphism, whereas the other chondrules (\#1 and \#3) became closed systems more than $11 \mathrm{Ma}$ after the peak metamorphism. Using a typical thermal diffusivity of chondrites, $k \sim 5 \times 10^{-7} \mathrm{~m}^{2} / \mathrm{s}$ (Yomogida and Matsui, 1983) and the relationship $x^{2} \sim k t$ where $x$ is diffusion distance and $t$ is diffusion time, the old chondrule \#2 in Sahara 99531 is expected to be located $\sim 5 \mathrm{~km}$ deep from the surface whereas the other younger chondrules (\#1 and \#3) are located $\geq 13(\mathrm{k}) \mathrm{m}$ deep from the surface. NWA 753 is located at $\sim 8 \mathrm{~km}$ deep from the surface. These are very crude estimate and only the relative location (rather than the absolute depth) is significant. Furthermore, if the $\mathrm{Mn}-\mathrm{Cr}$ ages reflect impact disruption that terminated the slow cooling process then such a calculation is meaningless.

A remaining question is whether the old chondrule \#2 in Sahara 99531 became a closed system during slow cooling or whether it became a closed system by rapid cooling as a result of impact excavation. The average $\mathrm{Mn} / \mathrm{Cr}$ ratio in the chondrule \#2 is only slightly lower than that in the chondrule \#3, suggesting similar thermal histories experienced by these chondrules. If closure of the $\mathrm{Mn}-\mathrm{Cr}$ system occurred during slow cooling, then we should expect similar $\mathrm{Cr}$ isotope anomalies for these chondrules. In reality, the $\mathrm{Cr}$ isotopic compositions are different (though admittedly the errors are large). This suggests that there was another factor (excavation by impacts) in addition to slow metamorphic cooling that affected the closure of the Mn-Cr system.

All chondrules from lithology-B in NWA 753 show identical ages within the respective errors. This suggests that they were derived from a restricted depth range in the parent body. They may be excavated and emplaced by a single impact event. Absence of solar rare gases in this chondrite is consistent with this interpretation. In contrast, chondrules from Sahara 99531 show a wide range of ages, suggesting that they were derived from various locations of the parent body. Presence of solar rare gases in this chondrite is consistent with this interpretation. Future study of $\mathrm{Mn}-\mathrm{Cr}$ dating of olivine in other $\mathrm{R}$ chondrites will reveal if such a relationship between the age range and the presence of solar rare gases holds generally for $\mathrm{R}$ chondrites.

A large proportion of $\mathrm{R}$ chondrites is petrologic type 3 in contrast to a rather small proportion in ordinary chondrites. This suggests that the $\mathrm{R}$ chondrites parent body was not heated to very high temperatures. Possible explanations for this observation are 1) the parent body was small, 2) the parent body accreted late and 3) a large amount of water served as a coolant, similar to the case of CI-CM chondrites. Many R chondrites are regolith breccias, suggesting that the size of the parent-body is not very small. Therefore, the first explanation is unlikely. The accretion time scale of planetesimals strongly depends on the distance from the sun (Nakagawa et al., 1983). But the difference in the accretion time scale within the asteroidal belt is probably not longer than $1 \mathrm{Ma}$, judging from the numerical simulation of Nakagawa et al. (1983). Therefore, the main factor that determined the smaller degree of metamorphism of $\mathrm{R}$ chondrites may be high water contents in the parent body.

Mn concentrations in Fe-rich olivine in $\mathrm{R}$ chondrites (including primitive ones like ALH 85151) are nearly constant at $\mathrm{MnO}=0.4 \sim 0.5$ wt. $\%$. This suggests that $\mathrm{Mn}$ concentration in Fe-rich olivine was established early and held constant during the metamorphic history. In contrast, $\mathrm{Cr}$ concentrations in olivine are quite variable. Grossman and Brearley (2005) made a detailed study of $\mathrm{Cr}$ in olivine in ordinary and $\mathrm{CO}$ chondrites and concluded that $\mathrm{Cr}$ diffused out of olivine at very low temperatures. Since the $\mathrm{Cr}$ diffusion rate in olivine is not fast compared with those of other cations (Ito and Ganguly, 2006), the Cr loss was probably promoted by the presence of water. By analogy, Cr loss from olivine and formation of chromite probably started early in the metamorphic history of R chondrites, in the presence of water. At higher temperatures $\mathrm{Cr}$ loss from olivine continued presumably under a dry condition. In the case of NWA 753 and the old chondrule \#2 in Sahara 99531, olivine became a closed system early by impact excavation while ${ }^{53} \mathrm{Mn}$ was still extant. Younger chondrules in Sahara 99531 were kept above the closure temperature for a long time and when the olivine became a closed system, ${ }^{53} \mathrm{Mn}$ was already practically extinct.

\section{Conclusions}

$\mathrm{Mn}-\mathrm{Cr}$ systematics suggests that olivine grains in the lithology-B of NWA 753 became closed systems at $\sim 4560$ Ma. Mn-Cr ages of olivine in Sahara 99531 range from less than 4553 Ma to 4562 Ma. Young Mn-Cr ages of olivine grains in $\mathrm{R}$ chondrites probably correspond to closure during slow cooling from the peak metamorphic temperature, whereas older ages probably reflect closure by rapid cooling associated with impact excavation. Abundant water in the $\mathrm{R}$ chondrite parent body may have served as a coolant that kept the parent body as a whole cooler than ordinary chondrites and may have contributed to the early closure of olivine. The water also promoted loss of $\mathrm{Cr}$ from olivine, making the $\mathrm{Mn}-\mathrm{Cr}$ dating possible for $\mathrm{R}$ chondrites.

Acknowledgments. We are thankful to Drs. X. Hua and L. Nyquist for constructive review. This work was supported by grants-in-aid of science research (14340169) from the Japanese Society for the Promotion of Science. This research benefited from discussion with Dr. H. Hiyagon.

\section{References}

Amelin, Y., A. N. Krot, I. D. Hutcheon, and A. A. Ulyanov, Lead isotopic ages of chondrules and calcium-aluminum-rich inclusions, Science, 297, 1678-1683, 2002.

Baker, J., M. Bizzaro, N. Wittig, J. Connelly, and H. Haack, Early planetesimal melting from an age of 4.5562 Gyr for differentiated meteorites, 
Nature, 436, 1127-1131, 2005.

Bischoff, A., Mineral characterization of primitive, type -3 lithologies in Rumuruti chondrites, Meteoritics \& Planet. Sci., 35, 699-706, 2000.

Bischoff, A., T. Geiger, H. Palme, B. Spettel, L. Schultz, P. Scherer, T. Loeken, P. Bland, R. N. Clayton, T. K. Mayeda, U. Herpers, B. Meltzow, R. Michel, and B. Dittrich-Hannen, Acfer 217-A new member of the Rumuruti chondrite group (R), Meteoritics, 29, 264-274, 1994.

Bischoff, A. and G. Srinivasan, Mg-26 excess in hibonites of the Rumuruti chondrite Hughes 030, Meteorotics \& Planetary Sci., 38, 5-12, 2003.

Dixon, E. T., D. D. Bogard, and D. H. Garrison, ${ }^{39} \mathrm{Ar}^{-}{ }^{40} \mathrm{Ar}$ chronology of R chondrites, Meteoritics \& Planetary Sci., 38, 341-355, 2003.

Ebisawa, N., J. Park, and K. Nagao, Noble gases in Northwest Africa 753 (NWA 753), Rumuruti chondrites, Geochim. Cosmochim. Acta, 67(A84), 2003.

Greenwood, J. P., A. E. Rubin, and J. T. Wasson, Oxygen isotopes in R-chondrite magnetite and olivine: Links between $\mathrm{R}$ chondrites and ordinary chondrites, Geochim. Cosmochim. Acta, 64, 3897-3911, 2000.

Grossman, J. N. and A. J. Brearley, The onset of metamorphism in ordinary and carbonaceous chondrites, Meteoritics \& Planetary Sci., 40, 87-122, 2005.

Hsu, W., Mn-Cr systematics of pallasites, Geochem. J., 39, 311-316, 2005.

Hua, X., G. R. Huss, S. Tachibana, and T. G. Sharp, Oxygen, silicon, and $\mathrm{Mn}-\mathrm{Cr}$ isotopes of fayalite in the Kaba oxidized CV3 chondrite: Constraints for its formation history, Geochim. Cosmochim. Acta, 13331348, 2005.

Ito, M. and J. Ganguly, Diffusion kinetics of $\mathrm{Cr}$ in olivine and ${ }^{53} \mathrm{Mn}-{ }^{53} \mathrm{Cr}$ thermo-chronology of early solar system objects, Geochim. Cosmochim. Acta, 70, 799-809, 2006.

Kallemeyn, G. W., A. E. Rubin, and J. T. Wasson, The compositional classification of chondrites 7. The R chondrite group, Geochim. Cosmochim Acta, 60, 2243-2256, 1996.

Kita, N., H. Nagahara, S. Togashi, and Y. Morishita, A short duration of chondrule formation in the solar nebula: Evidence from ${ }^{26} \mathrm{Al}$ in Semarkona ferromagnesian chondrules, Geochim. Cosmochim. Acta, 64, 3913-3922, 2000.

Krot, A. N., A. J. Brearley, M. Petaev, G. W. Kallemeyn, D. W. G. Sears, P. Benoit, I. D. Hutcheon, M. E. Zolensky, and K. Keil, Evidence for low temperature growth of fayalite and hedenbergite in MacAlpine Hills
88107, an ungrouped carbonaceous chondrites related to the CM-CO clan, Meteoritics \& Planetary Sci., 35, 1365-1386, 2000.

Lugmair, G. W. and A. Shukolyukov, Early solar system timescales according to ${ }^{53} \mathrm{Mn}-{ }^{53} \mathrm{Cr}$ systematics, Geochim. Cosmochim. Acta, 62, $2863-$ 2886, 1998.

Nakagawa, Y., C. Hayashi, and K. Nakazawa, Accumulation of planetesimals in the solar nebula, Icarus, 54, 361-376, 1983.

Nyquist, L., L. Lindstrom, D. Mittlefehldt, C.-Y. Shih, H. Weismann, S. Wentworth, and R. Martinez, Manganese-chromium formation intervals for chondrules from the Bishumpur and Chainpur meteorites, Meteoritics \& Planetary Sci., 36, 911-938, 2001.

Rubin, A. and G. W. Kallemeyn, Pecora Escarpment 91002: A member of the new Rumuruti (R) chondrite group, Meteoritics, 29, 255-264, 1994.

Schultz, L. and H. W. Weber, The irradiation history of Rumurutichondrites, 26th Symp. Ant. Met. p.128, 2001.

Schultz, L., H. W. Weber, and L. Franke, Rumuruti chondrites: Noble gases, exposure ages, pairing, and parent body history, Meteoritics \& Planetary Sci., 40, 557-571, 2005.

Schulze, H., A. Bischoff, H. Palme, B. Spettel, D. Dreibus, and J. Otto, Mineralogy and chemistry of Rumuruti: The first meteorite fall of the new R chondrite group, Meteoritics, 29, 275-286, 1994.

Sugiura, N. and H. Hoshino, Mn-Cr chronology of five IIIAB iron meteorites, Meteoritics \& Planet. Sci., 38, 117-144, 2003.

Sugiura, N., A. Miyazaki, and K. Yanai, Widespread magmatic activities on the angrite parent body at $4562 \mathrm{Ma}$ ago, Earth Planets Space, 57, e13-e16, 2005.

Turner, G., M. C. Enright, and P. H. Cadogan, The early history of chondrites parent bodies inferred from ${ }^{40} \mathrm{Ar}-{ }^{39} \mathrm{Ar}$ ages, Proc. 9th Lunar Planet. Sci. Conf., pp. 989-1025, 1978.

Weisberg, M. K., M. Prinz, H. Kojima, K. Yanai, R. N. Clayton, and T. K. Mayeda, The Carlisle Lakes-type chondrites: A new grouplet with high $\delta^{17} \mathrm{O}$ and evidence for nebula oxidation, Geochim. Cosmochim. Acta, 55, 2657-2669, 1991.

Yomogida, K. and T. Matsui, Physical-properties of ordinary chondrites, $J$. Geophys. Res., 88, 9513-9533, 1983.

N. Sugiura (e-mail: sugiura@eps.s.u-tokyo.ac.jp) and A. Miyazaki 